\title{
초기 척추관절병증과 혼동되었던 체간 근육의 위약을 동반한 근지대형 근디스트로피, 2A형: 증례 보고
}

권사라, 김대열

울산대학교 서울아산병원 재활의학과

\section{Limb-Girdle Muscular Dystrophy Type 2A (Calpainopathy) with Axial Muscle Weakness Mimicking Spondyloarthropathy: A Case Report}

\author{
Sara Kwon, Dae Yul Kim \\ Department of Rehabilitation Medicine, Asan Medical Center, University of Ulsan College of Medicine, Seoul, Korea
}

\begin{abstract}
Limb-girdle muscular dystrophy (LGMD) is a hereditary myopathy characterized by weakness and wasting of pelvic girdle musculature. Herein, we report the case of a 51-year-old man with an unremarkable past medical history who presented with insidious onset of weakness in his back and proximal lower extremities. Clinical findings and electrodiagnostic tests were consistent with myopathy. Exome sequencing detected a mutation in calpain-3 (CAPN3), which confirmed the diagnosis of LGMD 2A. Through a review of less typical case of LGMD 2A, we confirmed that the severity and onset of symptoms may vary according to the quantity of CAPN3 expressed in patients with mutations in CAPN3.
\end{abstract}

Key Words: limb-girdle muscular dystrophy, limb-girdle muscular dystrophy type 2A, calpainopathy

\section{Introduction}

Limb-girdle muscular dystrophy (LGMD) refers to a heterogeneous group of childhood or adult onset muscular dystrophies that are distinct from X-linked dystrophinopathies such as Duchenne muscular dystrophy and Becker muscular dystrophy (BMD). ${ }^{1,2}$ Af-

Received May 10, 2018

Revised October 25, 2018

Accepted February 26, 2019

Corresponding Author: Dae Yul Kim

Department of Rehabilitation Medicine, Asan Medical Center, University of Ulsan College of Medicine, 88 Olympic-ro 43-gil, Songpa-gu, Seoul 05505, Korea

Tel: 82-2-3010-3793, Fax: 82-2-3010-6964, E-mail: dykimsmart@gmail.com fected individuals typically present with weakness and wasting confined to the proximal limb musculature with relative sparing of the bulbar muscles. LGMD is classified as type 1 or 2 according to the dominant or recessive mode of inheritance. ${ }^{1}$ Autosomal-recessive inherited LGMD accounts for approximately 90\% of all patients with LGMD. ${ }^{3}$ The most common form of LGMD is LGMD 2A, which is caused by mutations in the calpain-3 (CAPN3) gene. Here, we report the case of a patient who presented with difficulty in flexing and extending his back and in climbing stairs.
Copyright $\odot$ by Korean Association of EMG Electrodiagnostic Medicine
This is an Open Access article distributed under the terms of the Creative Commons Attribution Non-Commercial License (http://creativecommons.org/licenses/by-nc/4.0) which permits unrestricted non-commercial use, distribution, and reproduction in any medium, provided the original work is properly cited. 


\section{Case Report}

A 51-year-old man presented with complaints of difficulty in climbing stairs without the aid of the railing at the outpatient clinic of the Department of Rehabilitation Medicine. His medical history included the occurrence of low back pain 12 years ago, which had improved after treatment with acupuncture. However, since the past 5 years, he had started experiencing difficulty in bending his waist and had visited a local orthopedic clinic. The doctor attributed the symptoms to weakness of back muscles and suggested ankylosing spondylitis. However, the patient did not seek further evaluation and underwent only physical therapy. Recently, the patient's workplace had changed and he occasionally had to lift approximately $15 \mathrm{~kg}$ of electronic components. However, he experienced difficulty in flexing and extending his back for this purpose. The symptoms worsened, and eventually, he faced difficulty in climbing stairs without the support of the railing. Moreover, he experienced difficulty while walking uphill or while walking for more than $30 \mathrm{~min}$. His past medical history and family history was unremarkable. On physical examination, muscle strength was assessed according to the Medical Research Council (MRC) scale; muscle strength in the upper extremities was intact. He scored $4 / 2$ on flexion and extension of bilateral hip joint, 4/4 on flexion and extension of both knees, and $5 / 5$ on dorsiflexion and plantar flexion of the ankle and big toe. Deep tendon reflexes were slightly hypoactive in both the upper and lower extremities. No tenderness was observed over the lumbar spinous processes, paravertebral muscles, or the sacroiliac joint. The fingerto-floor distance was not measurable because he was unable to flex his back. To evaluate the possibility of ankylosing spondylitis, blood tests, including HLA-B27, and bone single photon emission computed tomography (SPECT) were performed. HLA-B27, quantitative rheumatoid factor, and anti-nuclear antibody were all negative. Bone SPECT revealed the degenerative spondylosis of the lumbar spine but did not show definite abnormalities of the sacroiliac joints. Routine blood tests showed a slight elevation of serum alanine transferase and aspartate transferase levels (81 IU/L and 49 IU/L, respectively).

To evaluate the possibility of neuromuscular disease, nerve conduction studies and electromyography were performed. Nerve conduction studies were normal; however, the motor unit action potential recorded in the proximal muscles showed a shorter duration and polyphasic features with an early recruitment pattern that was consistent with myopathy. The right biceps brachii and right iliopsoas muscles showed abnormal spontaneous activity at rest (Table 1). Further detailed physical examination revealed neck extensor weakness (grade 4 on the MRC scale) and mild pseudohypertrophy of the calf (Fig. 1). Walking test revealed a hyperlordotic gait; Gower's sign was observed on asking the

Table 1. Findings of Needle Electromyography

\begin{tabular}{|c|c|c|c|c|c|c|c|c|}
\hline \multirow{2}{*}{ Muscle } & \multicolumn{3}{|c|}{ Spontaneous activity } & \multicolumn{3}{|c|}{ Motor unit action potential } & \multirow{2}{*}{$\begin{array}{c}\text { Recruitment } \\
\text { Pattern }\end{array}$} & \multirow{2}{*}{$\begin{array}{c}\text { Interference } \\
\text { Pattern } \\
\end{array}$} \\
\hline & Fib & PSW & Fasc & Amplitude & Duration & Phase & & \\
\hline \multicolumn{9}{|l|}{ Right } \\
\hline RF & - & - & - & Normal & Short & Polys & Early & Full \\
\hline IP & - & + & - & Normal & Short & Polys & Early & Reduced \\
\hline GCM & - & - & - & Normal & Normal & Normal & Normal & Full \\
\hline $\mathrm{BF}(\mathrm{L})$ & - & - & - & - & - & - & No MUAP & No MUAP \\
\hline $\mathrm{GM}$ & - & - & - & Normal & Short & Polys & Early & Reduced \\
\hline $\mathrm{BB}$ & - & + & - & Normal & Short & Polys & Early & Reduced \\
\hline L4 PSM & - & - & - & & & & & \\
\hline
\end{tabular}

Fib: fibrillation, PSW: positive sharp wave, Fasc: fasciculation, RF: rectus femoris, IP: iliopsoas, GCM: gastrocnemius, BF(L): biceps femoris long head, GM: gluteus maximus, BB: biceps brachii, PSM: paraspinal muscle, MUAP: motor unit action potential *Muscle selections were done in unilateral side for possibility of muscle biopsy 

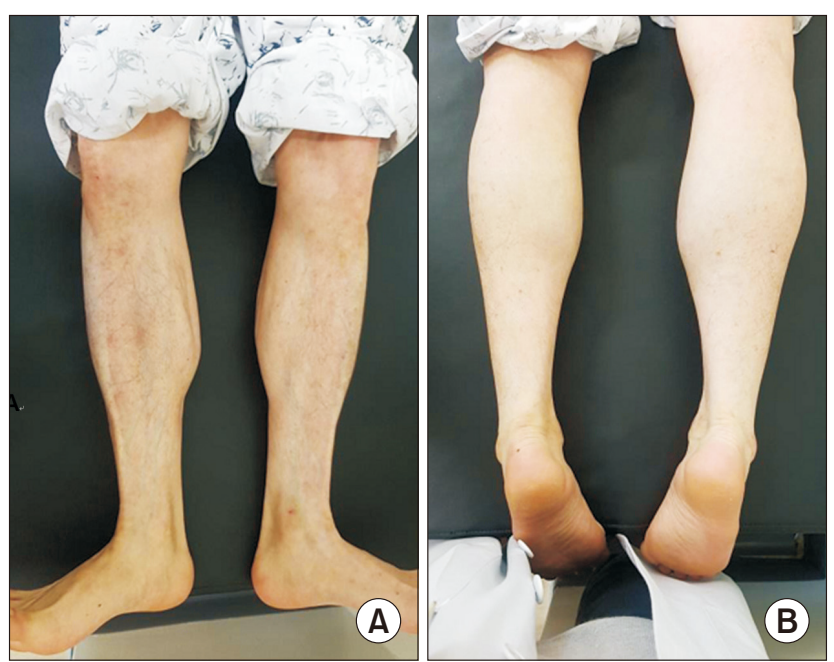

Fig. 1. Photograph of the patient showing pseudohypertrophy of the calf.

patient to stand from a sitting position. Additionally, blood tests revealed elevated creatine kinase level (1791 IU/L; normal range: 50 250 IU/L). Whole spine radiograph revealed thoracic curve scoliosis with the apex at T8; the Cobb's angle was $18^{\circ}$ (Fig. 2). Review of the lumbar magnetic resonance imaging performed 5 years back showed severe fatty degenerative changes of axial muscles in the lumbar area that had already progressed (Fig. 3).

Based on the above results, we proceeded with genetic testing to confirm the diagnosis. Genetic tests were performed for BMD, including for deletion and duplication mutations. Furthermore, diagnostic exome sequencing was performed to test for other myopathic diseases. The results showed two mutations in CAPN3 associated with LGMD type 2A. One was a mutation of exon 19, c.2069_2070del resulting in Frameshift, whereas, the other was c. $2120 \mathrm{~A}>\mathrm{G}$ at exon 20 , resulting in missense. These mutations have been reported before. ${ }^{4-6}$ After confirming the genetic diagnosis, muscle biopsy of the left deltoid muscle was performed. The specimen showed no definite abnormal findings (Fig. 4).

\section{Discussion}

LGMD is caused by a mutation within the dystrophin-

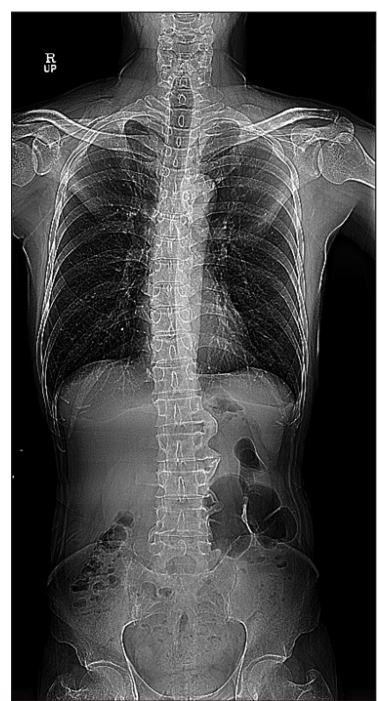

Fig. 2. Radiograph of whole spine. Mild thoracic curve scoliosis with $18^{\circ}$ of Cobb's angle is shown.

glycoprotein complex and the related proteins including sarcoglycan. Reports on the prevalence of LGMD are limited because of the heterogeneity of the condition and the lack of diagnostic specificity without genetic testing. The estimated prevalence for all forms of LGMD range from 1 in 14,500 to 1 in 123,000. ${ }^{2}$

In the present case, the patient showed axial and proximal weakness beginning at a relatively late age with insidious progression. At presentation, ankylosing spondylitis was considered because of the patient's history of low back pain and recent difficulty in flexing and extending his back. LGMD 2A is caused by mutation in $C A P N 3$, which encodes for a muscle-specific member of a family of $\mathrm{Ca}^{2+}$-activated neutral proteases. ${ }^{2,5,7}$ CAPN3 is located in chromosome $15 q 15.1$. Calpainopathy demonstrates a wide clinical variability that ranges from mild to severe. Early-onset_during first to second decade of life-and symmetrical limbgirdle weakness is the most common phenotype of calpainopathy i.e., LGMD 2A; scapulohumeral phenotype, rigid spine syndrome, and asymptomatic hyperCKemia have also been reported. ${ }^{6,8,9}$

In the present case, initial symptoms manifested as back pain during the late forties. In cases of calpainopathy with a later age of onset, axial muscle involvement 

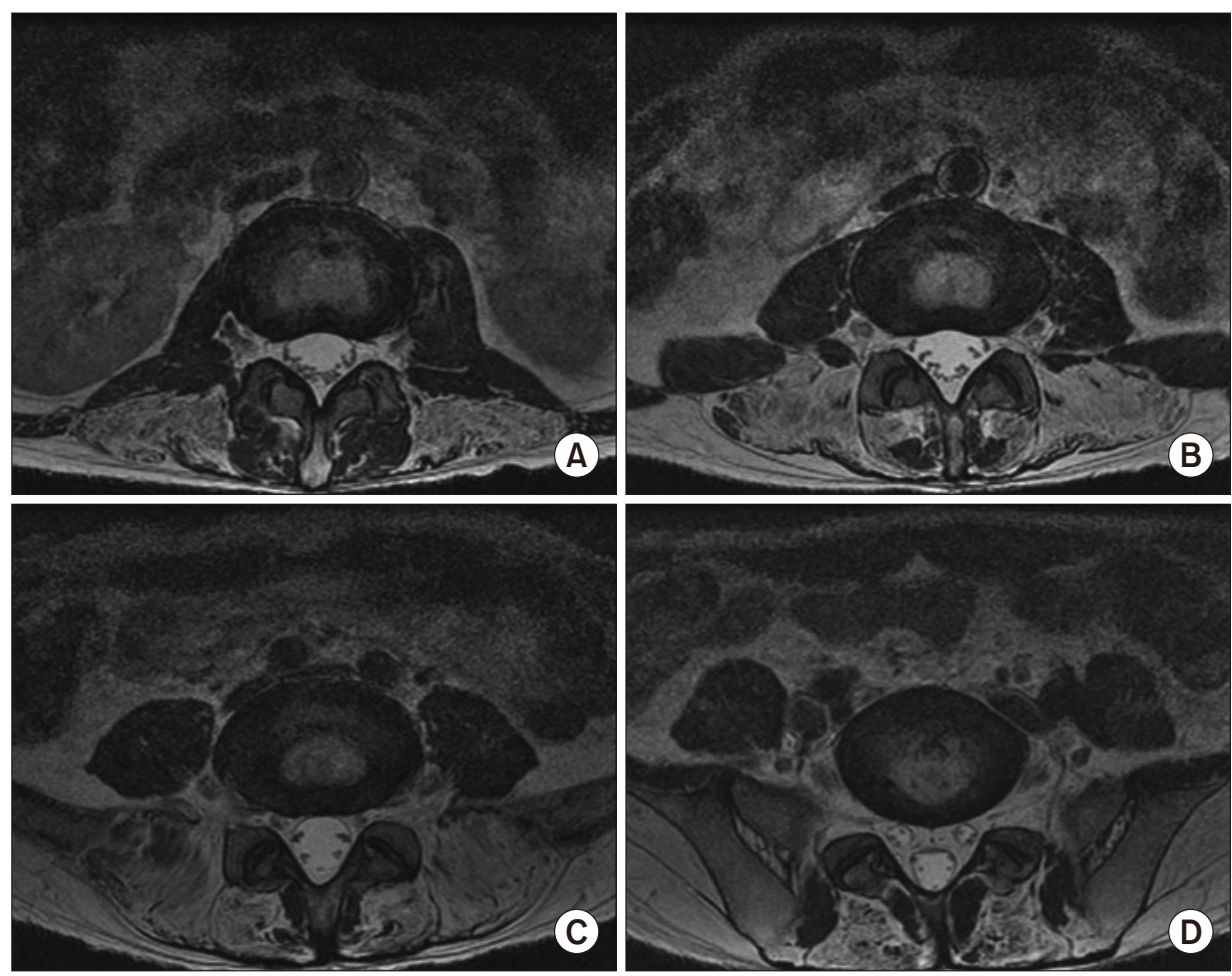

Fig. 3. Lumbar magnetic resonance imaging. Diffuse fatty degenerative changes of multifidus and erector spinae are observed in $\mathrm{T} 2$ weighted axial views. (A) L2-3, (B) L3-4, (C) L4-5, (D) L5-S1.
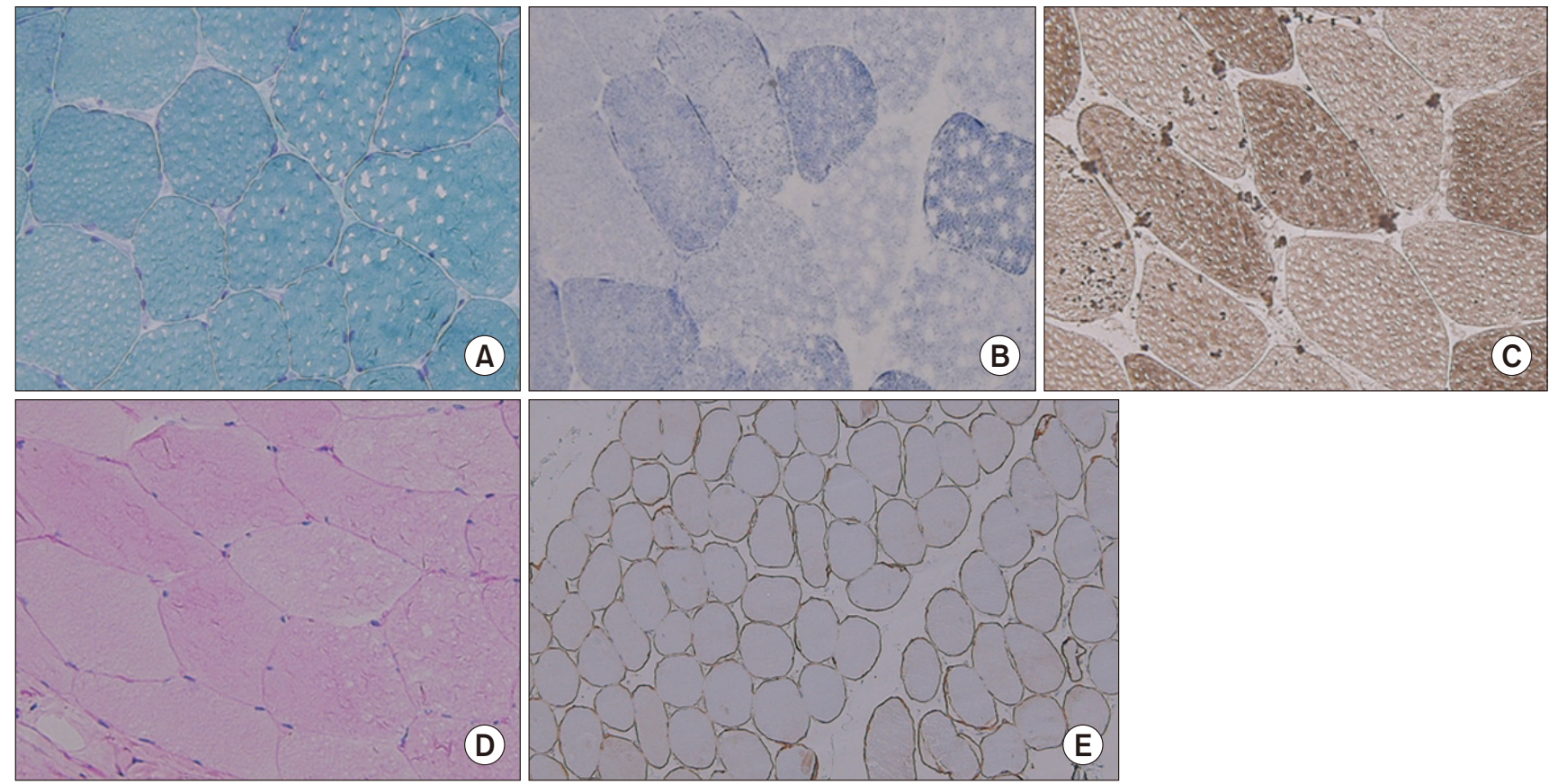

Fig. 4. Histopathology. (A) Modified Gomori Trichrome staining showing no signs of endomysial fibrosis. (B, C) NADH and ATPase staining showing normal proportion of fiber types. (D) Periodic acid-Schifff special staining showing no deposition of glycogen. (E) Immunohistochemical staining of dystrophin showing normal expression levels.

tends to occur with back pain. ${ }^{10}$ Axial muscle involvement may cause camptocormia (bent spine syndrome), and it is necessary to differentiate the condition from
Parkinson disease, motor neuron disease, and axial myopathies. In addition, as in the present case, a rigid spine may mimic ankylosing spondylitis. ${ }^{10}$ This patient 
showed symptoms of axial muscle involvement rather than the typical characteristics of LGMD 2A: back pain, rigid spine, axial weakness, and degeneration of axial paraspinalis muscles.

Histopathological findings of patients with calpainopathy who have disease progression include increased variability in fiber size, fibrosis, regeneration, degeneration, and increased lobulated fibers; however, these findings are not specific to calpainopathy. ${ }^{6,10}$ In the present case, the left deltoid muscle biopsy revealed no abnormalities; this could be attributed to sampling of a less affected muscular site. Park et al. (2016) have studied 13 patients with LGMD 2A and analyzed the results of muscle biopsy in 9 patients. Of these nine patients, three had normal findings on muscle biopsy, and they were clinically asymptomatic to mildly symptomatic at the time of biopsy. ${ }^{6}$ Because prominent axial muscle involvement was observed in the present patient, biopsy specimen from other sites, such as the lumbar paraspinalis muscles, may have yielded different results.

As mentioned above, the muscle biopsy may yield no specific findings; therefore, CAPN3 immunohistochemical or immunoblot analysis is typically performed. However, CAPN3immunohistochemical analysis is useful only for screening of complete CAPN3 protein deficiency. Furthermore, although CAPN3 immunoblot analysis is considered to be a powerful detection method that identifies approximately $80 \%$ of primary defects, it is not an entirely sensitive method for the diagnosis of LGMD 2A because approximately 20 30\% of these patients have normal quantity of the protein. Therefore, genetic analysis for the detection of mutation in CAPN3 is the diagnostic gold standard for patients having normal protein quantity but with a high suspicion index for calpainopathy. Hence, the nextgeneration sequencing (NGS)-based targeted exome sequencing for screening genomic DNAs of almost all neuromuscular diseases is emerging as a useful diagnostic tool for identifying mutations in both known and novel genes in patients with LGMD, as observed in the present case. $^{11}$
Here, we report a rare case of a patient with late-onset axial myopathy who was eventually diagnosed with LGMD 2A. We advocate the process of approaching the diagnosis of LGMD 2A using NGS-based targeted exome sequencing, which is considered as the gold standard for the diagnosis of LGMD 2A. ${ }^{11}$

\section{References}

1. Dumitru D, Amato AA, Zwarts MJ: Electrodiagnostic medicine, 2nd ed, Philadelphia: Hanley \& Belfus, 2002

2. Pegoraro E, Hoffman EP: Limb-girdle muscular dystrophy overview. In: Adam MP, Ardinger HH, Pagon RA, Wallace SE, Bean LJH, Stephens K, et al, editors. GeneReviews ${ }^{\circledR}$, Seattle (WA): University of Washington, Seattle, 1993-2018

3. van der Kooi AJ, Barth PG, Busch HF, de Haan R, Ginjaar HB, van Essen AJ, et al: The clinical spectrum of limb girdle muscular dystrophy. A survey in the Netherlands. Brain 1996: 119: 1471-1480

4. Richard I, Roudaut C, Fougerousse F, Chiannilkulchai N, Beckmann JS: As STS map of the limb girdle muscular dystrophy type 2A region. Mamm Genome 1995: 6: 754-756

5. Shin JH, Kim HS, Lee CH, Kim CM, Park KH, Kim DS: Mutations of CAPN3 in Korean patients with limb-girdle muscular dystrophy. J Korean Med Sci 2007: 22: 463-469

6. Park HJ, Jang H, Lee JH, Shin HY, Cho SR, Park KD, et al: Clinical and pathological heterogeneity of korean patients with CAPN3 mutations. Yonsei Med J 2016: 57: 173-179

7. Angelini C, Nardetto L, Borsato C, Padoan R, Fanin M, Nascimbeni AC, et al: The clinical course of calpainopathy (LGMD2A) and dysferlinopathy (LGMD2B). Neurol Res 2010: 32: $41-46$

8. Angelini C, Fanin M: Calpainopathy. In: Adam MP, Ardinger HH, Pagon RA, Wallace SE, Bean LJH, Stephens K, et al, editors. GeneReviews $^{\circledR}$, Seattle (WA): University of Washington, Seattle, 1993-2018

9. Urtasun M, Saenz A, Roudaut C, Poza JJ, Urtizberea JA, Cobo AM, et al: Limb-girdle muscular dystrophy in Guipuzcoa (Basque Country, Spain). Brain 1998: 121: 1735-1747

10. Liewluck T, Goodman BP: Late-onset axial myopathy and camptocormia in a calpainopathy carrier. J Clin Neuromuscul Dis 2012: 13: 209-213

11. Fanin M, Angelini C: Protein and genetic diagnosis of limb girdle muscular dystrophy type $2 \mathrm{~A}$ : the yield and the pitfalls. Muscle Nerve 2015: 52: 163-173 